\title{
Irrigation of Maxillary Sinus through Middle Meatus versus Inferior Meatus: A Randomized Controlled Trial
}

Matin MA ${ }^{1 *}$, Raquib A ${ }^{2}$, Azad $\mathrm{AK}^{3}$ and Ahsan $\mathrm{Z}^{4}$

${ }^{1}$ Professor of Otolaryngology and Head, Shaheed Suhrawardy Medical College \& Hospital, Bangladesh

${ }^{2}$ Associate Professor ENT, Popular Medical College, Bangladesh

${ }^{3}$ Senior Consultant, Paediatrics, Khulna Medical College, Bangladesh

${ }^{4}$ Associate Professor ENT, TMSS Medical College, Bangladesh

*Corresponding author: Mohammad Abdul Matin, Professor and Head of the Department of ENT, Shaheed Suhrawardy Medical College and Hospital, Dhaka 1207, Bangladesh, Email: matinfrcs@yahoo.com

\section{Abstract}

Objective: To stimulate interest in irrigation of maxillary sinus through middle meatus and to compare this new technique of irrigation with antral wash through the inferoir meatus regarding it's efficacy and complications.

Methods: A total of 40 patients of chronic maxillary sinusitis or unresolved acute maxillary sinusitis were selected, 20 for middle meatus and 20 for inferior meatus irrigation, patients were randomly selected, middle meatal puncture was done by Karl Storz antrum sucker nozzle using 0 degree telescope and inferior meatus by Litzwiz antrum trocher and cannula. Any difficulties or complications were noted

Results: The age of the patients ranged from 12-55 years, with mean age 34.9 years in middle meatal group and 38.7 years in inferior meatal group. There were 25 male and 15 female patients with male female ratio 1.67:1. No difficulties or any comlications were noted in middle meatus group whereas mispuncture, failure of puncture, haemorrhage and check swelling were noted in some patients of inferior meatus group.

Conclusion: It is concluded that this new technique of puncturing the middle meatus is a safe, easy and effective procedure of irrigation of the maxillary sinus instead of antral wash out via the inferior meatus for the treatment of chronic maxillary sinusitis

Keywords: Irrigation; Middle meatus; Antral wash; Inferior meatus

Abbreviations: AERD: Aspirin Exacerbated Respiratory Disease; CRS: Chronic Rhinosinusitis; RARS: Recurrent Acute Rhinosinusitis; MMA: Middle Meatalantrostomy; CRSwNP: Chronic Maxillary Sinusitis with Nasal Polyps.

\section{Introduction}

The term sinusitis is now changed to rhino sinusitis as the mucosa of the paranasal sinuses are in direct contact with the nasal cavity [1]. Rhinosinusitis is a relatively common 


\section{Otolaryngology Open Access Journal}

disease affecting $6-15 \%$ of the population each year [2]. CRS is defined by the American Academy of Otolaryngology Head and Neck Surgery as 12 weeks, or longer, of two of a defined group of symptoms/signs: mucopurulent drainage, nasal congestion, facial pressure/pain, or decreased sense of smell and inflammation documented by one of the following: purulent mucus on endoscopy, polyps in the nasal cavity, or radiographic imaging showing inflammation [3]. Over the past decade, patients with CRS have been frequently subdivided into two main categories based on their specific pathophysiology: CRS with nasal polyps (CRSwNP) vs. CRS without nasal polyps (CRSsNP) [4]. There are many factors which can cause or influence the severity of chronic rhino sinusitis including asthma, aspirin exacerbated respiratory disease (AERD), cystic fibrosis and immunodeficiency [5]. Medical treatment of chronic rhino sinusitis usually commences with nasal saline irrigations, topical nasal steroids, nasal decongestant, oral antibiotics, and possibly oral steroids [3]. However, medical management often times fails to sufficiently alleviate the patient's symptoms, and, for these patients, surgical intervention may be considered to be a logical next step in their treatment. Surgical management is needed for two main subcategories: chronic rhinosinusitis (CRS) and recurrent acute rhinosinusitis (RARS). For chronic maxillary sinusitis there are four surgical options which include antral wash out, intranasal antrostomy, Cald Well Luc operation and FESS. Osteomeatal complex block causing chronic sinusitis can be treated with simple middle meatal antrostomy (MMA) and anterior ethmoidectomy (Mini FESS) but in extensive polypoid diseases with sinusitis a more complete fronto-spheno-ethmoidectomy (full house FESS) is needed [2]. In recent years a minimally invasive options such as balloon sinus dilatation are now available [6].

\section{Materials and Methods}

This prospective randomized study was done at Maleka Nursing Home and Matin Specialized Hospital Hospital, Bogura and CDM Hospital Rajshahi from January 2001 to December 2015. All patients of radiologically confirmed chronic maxillary sinusitis and acute maxillary sinusitis not responding to medical treatment were included. The patients were selected considering exclusion and inclusion criteria. The procedure were done under local or general anaesthesia along with septoplasty operation in some cases. For middle meatal puncture Karl Storz antrum sucker nozzle and 0 degree telescope with or without TV monitor are used and for inferior meatal puncture, antrum trocher and cannula and killian's speculum are used (Figure 1). For irrigation of maxillary sinus through middle meatus five minutes after giving $10 \%$ xylocaine spray to the middle meatus, antrum sucker nozzole is gently pushed above the inferior turbinate towards the maxillary sinus through the uncinate process (uncinotomy). Once the cannula is in the maxillary sinus, it is irrigated with normal saline with the help of $50 \mathrm{cc}$ syring (Figure 2). Irrigation is continued until return fluid is clear. Antral wash was done to other group as usual way through the inferior meatus. Any difficulties or complications were noted in each group.

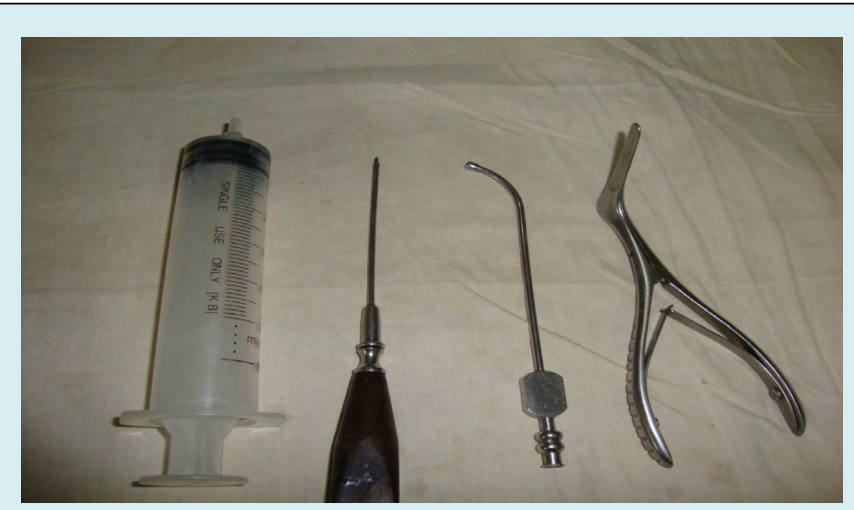

Figure 1: From left to right; 50 cc syring, Litzwiz antrum trocher and cannula. Karl Storz antrum sucker nozzle, Killian's nasal speculum.

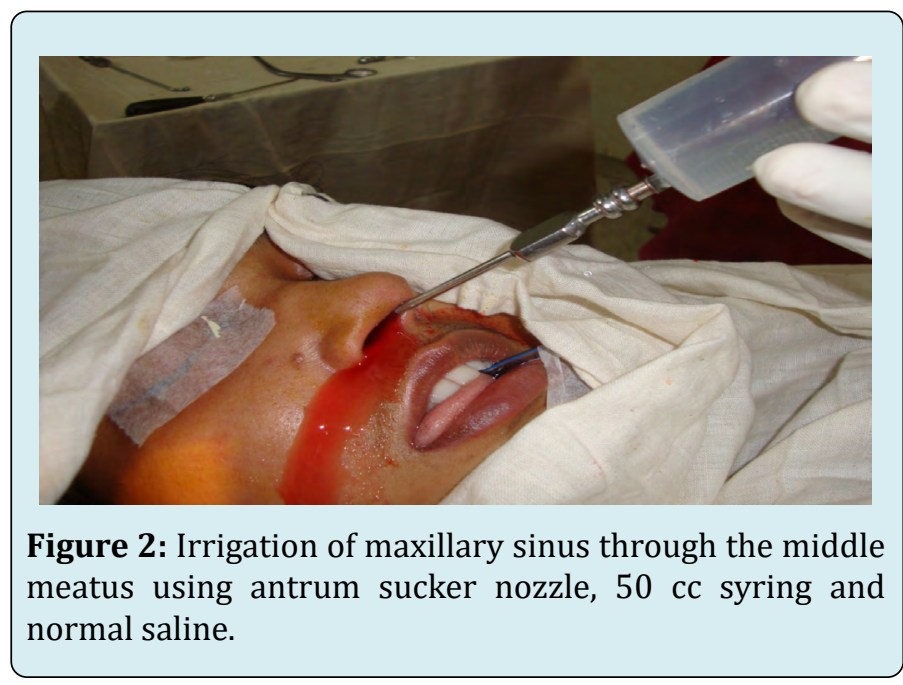

\section{Statistical Analysis}

The data collected was analyzed using SPSS version 20 and depicted using descriptive statistics

\section{Inclusion Criteria}

Patients with unilateral or bilateral chronic maxillary sinusitis and acute maxillary sinusitis not responding to medical treatment Septal deviation patients with maxillary sinusitis undergoing septoplasty operation. 


\section{Otolaryngology Open Access Journal}

\section{Exclusion Criteria}

Chronic maxillary sinusitis with nasal polyps (CRSwNP)

\section{Results}

Age of the patients ranged from 12-55 years with a mean age 34.9 years in middle meatal group and 38.7 in inferior meatal group (Table 1). There were 25 male and 15 female patients with male female ratio of 1.67:1 (Table 2). Any difficulties or complications of both procedures were noted in (Table 3).

\begin{tabular}{|c|c|c|}
\hline Age & $\begin{array}{c}\text { Middle meatal } \\
\text { group }\end{array}$ & $\begin{array}{c}\text { Inferior meatal } \\
\text { group }\end{array}$ \\
\hline Min & 12 & 18 \\
\hline Max & 55 & 50 \\
\hline Mean & 34.9 & 38.7 \\
\hline
\end{tabular}

Table 1: Age distribution (N-40).

\begin{tabular}{|c|c|c|}
\hline Sex & $\begin{array}{c}\text { Middle meatal } \\
\text { group }\end{array}$ & $\begin{array}{c}\text { Inferior Meatal } \\
\text { group }\end{array}$ \\
\hline Male & 13 & 12 \\
\hline Female & 10 & 5 \\
\hline M:F ratio 1.67:1 & & \\
\hline
\end{tabular}

Table 2: Sex distribution of patients (N-40).

\begin{tabular}{|c|c|c|}
\hline Observation & $\begin{array}{c}\text { Antral wash } \\
\text { through inferior } \\
\text { meatus }\end{array}$ & $\begin{array}{c}\text { Middle meatal } \\
\text { puncture }\end{array}$ \\
\hline $\begin{array}{c}\text { Fail to } \\
\text { puncture }\end{array}$ & 2 & None \\
\hline Feeling pain & moderate to severe & mild or no pain \\
\hline Mispuncture & 1 & None \\
\hline Haemorrhage & 3 & None \\
\hline Check swelling & 1 & None \\
\hline
\end{tabular}

Table 3: Any difficulties or complications of the two procedures.

\section{Discussion}

In adults, the maxillary sinuses are most commonly affected with acute and chronic sinusitis. Most of these cases can be managed with medications alone. When medical management failed to control the symptom of chronic maxillary sinusitis surgical intervention is frequently considered. Although functional endoscopic sinus surgery is becoming more popular by doing middle meatal antrostomy in the treatment of chronic maxillary sinusitis, irrigation of the maxillary sinuses or antral wash is still a gold standard of practice done by many of the ENT Surgeons. Although the more generally accepted method of irrigating the maxillary sinus is by the way of the inferior meatus using antral trocar and cannula this paper is presented primarily to stimulate interest in irrigation of the maxillary sinus through the middle meatus using Karl Storz antral sucker nozzle to puncture the middle meatus without telescope. I adopted this procedure out of interest when I faced some difficulties puncturing the inferior meatus with trocar and cannula like bleeding, failed to puncture or check swelling which are the recognized complications of antral wash out using trocar.

From that experiences I started doing irrigation through the middle meatus using antral sucker nozzole and I found this procedure very easy, effective and painless procedure without any complication. My aim of presenting this procedure is to encourage doctors who are still doing antral wash through the inferior meatus, so that they can adopt this technique. By searching internet it is found that the first paper of irrigation of the maxillary sinus through the middle meatus was presented by Mervin C Meyerson MD to the American Laryngologic, rhinologic and otological society in California, USA on 19 January 1958. Later he published this paper in the Laryngoscope Vol. 68, no 8 in 1958 [7] It has been noted by Mervin that it is easier to enter the maxillary sinus by the way of the middle meatus in children than adult

\section{Advantages}

a) Easy to puncture

b) Can be done without anaesthesia

c) No fail to puncture

d) No complications like bleeding, check swelling

e) Easy to puncture in children

However we should also remember the patho physiology behind some CRSsNP and many RARS patients is more often associated with an anatomic abnormality or localized obstruction rather than a pervasive inflammatory process $[8,9]$. For example, odontogenic sinusitis accounts for approximately $10-12 \%$ of RARS and typically presents when a dental abscess or periodontal disease infiltrates the maxillary sinus, resulting in localized sinusitis [10]. By relieving these local obstructions, such as the infected tooth, or other anatomic abnormalities, such as concha bullosa, infra orbitalethmoid cells (Haller cells), and accessory ostia, the disease process can often be halted with minimal surgical intervention.

\section{Conclusion}

It is concluded that this new technique of puncturing 


\section{Otolaryngology Open Access Journal}

the middle meatus is a safe, easy and effective procedure of irrigation of the maxillary sinus instead of antral wash out via the inferior meatus for the treatment of chronic maxillary sinusitis

\section{References}

1. Fokkens WJ, Lund VJ, Mullo J, Bachert C, Alobid I, et al. (2012) European position paper on rhinosinusitis and nasal polyps 2012. Rhinol Suppl 23: 1-298.

2. Watkinson JC, Clarke RW (2019) Surgical management of rhinusinusitis Scott-Brown's Otorhinolaryngology Head Neck surgery 1: 1059-1071.

3. Rosenfeld RM, Piccirillo JF, Chandrasekhar SS, Brook I, kumar KA, et al. (2015) Clinical practice guideline (update): Adult Sinusitis Executive Summary. Otolaryngol Head Neck Surg 152(4): 598-609.

4. Jiang XD, Li GY, Li L, Dong Z, Zhu DD (2011) The characterization of IL 17A expression in patients with chronic rhinusinusitis with nasal polyps. Am J Rhinol Allergy 25(5): 171-175.
5. Smith TL, Kern R, Palmer JN, Schlosser R, Chnadra RK, et al. (2013) Medical therapy vs surgery for chronic rhinusitis: a prospective, multi-Institutional study with 1 year follow-up. Int Forum Allergy Rhinol 3(1): 4-9.

6. Tomazic PV, Stammberger H, Braun H, Habermann W, Schmid C, et al. (2013) Feasibility of balloon sinuplasty in patients with chronic rhinosinusitis: The GRAz experience. Rhinology 51(2): 120-127.

7. Myerson MC (1958) Irrigation of maxillary sinus through the middle meatus. Laryngoscope 68(8): 1555-1565.

8. Jain R, Stow N, Douglas R (2013) Comparison of anatomical abnormalities in patients with limited and diffuse chronic rhinosinusitis. Int Forum Allergy Rhinol 3(6): 493-496.

9. Jorissen $M$, Hermans $R$, Bertrand $B$, Eloy $P$ (1997) Anatomical variations and sinusitis. Acta Otorhinolaryngol Belg 51(4): 219-226.

10. Mehra P, Murad H (2004) Maxillary sinus disease of odontogenic origin. Otolaryngol Clin North Am 37(2): 347-364.

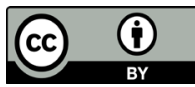

